\begin{tabular}{ll|l}
\cline { 2 - 3 } & \multicolumn{2}{l}{ Intervent Neurol 2017;6:117-125 } \\
\hline $\begin{array}{l}\text { DOI: 10.1159/000458161 } \\
\text { Published online: February 16, 2017 }\end{array}$ & $\begin{array}{l}\text { (C) 2017 S. Karger AG, Basel } \\
\text { www.karger.com/ine }\end{array}$ \\
\hline
\end{tabular}

\title{
Mechanical Thrombectomy for M2 Occlusions: A Single-Centre Experience
}

\author{
Pervinder Bhogala Philipp Bücke ${ }^{b} \quad$ Marta Aguilar Pérez ${ }^{a}$ \\ Oliver Ganslandt ${ }^{c}$ Hansjörg Bäzner ${ }^{b}$ Hans Henkes ${ }^{a}{ }^{d}$ \\ ${ }^{a}$ Neuroradiological Clinic, ${ }^{b}$ Neurological Clinic, and ${ }^{\mathrm{C} N e u r o s u r g i c a l ~ C l i n i c, ~}$ \\ Neurocenter, Klinikum Stuttgart, Stuttgart, and d Medical Faculty, University \\ Duisburg-Essen, Duisburg-Essen, Germany
}

\section{Keywords}

Stroke $\cdot$ Thrombectomy $\cdot M 2$

\begin{abstract}
Background: The recent success of several mechanical thrombectomy trials has resulted in a significant change in the management of patients presenting with stroke. However, questions still remain as to whether certain groups will benefit from mechanical thrombectomy. In particular, it is still uncertain whether mechanical thrombectomy should be performed in the M2 branches and, more generally, in the distal vasculature. Methods: We retrospectively analysed our prospectively maintained database of all patients undergoing mechanical thrombectomy between January 2008 and August 2016. We collected demographic, radiological, procedural and outcome data. Results: We identified 106 patients that met our inclusion criteria. The mean age of the patients was $68 \pm 13.8$ years, and there were 58 (54.7\%) male patients. Associated medical conditions were common with hypertension seen in $71 \%$ of the patients. The average Alberta Stroke Program Early CT (ASPECT) score on admission was $8.5 \pm 1$.7. The mean National Institutes of Health Stroke Scale score was $11.8 \pm 7.02$. The mean duration of the procedure was $103 \pm 3.4 \mathrm{~min}$, and the average number of thrombectomy attempts required was 1.8 (range 1-8). Angiographically, Thrombolysis in Cerebral Infarction Scale (TICI) $\geq 2 \mathrm{~b}$ was obtained in $90.5 \%$ of the patients. Five patients $(4.7 \%)$ had symptomatic intracranial haemorrhage on follow-up. At 90 -day follow-up, $54.6 \%$ of the patients had a modified Rankin Scale (mRS) score $0-2$, and $71.5 \%$ had an mRS score $\leq 3$. There were 15 deaths at 90 days (14.1\%). Conclusion: Mechanical thrombectomy in patients with solitary M2 clots is technically possible and carries a high degree of success with a good safety profile. Patients with confirmed M2 occlusion should be considered for mechanical thrombectomy.
\end{abstract}




\section{Introduction}

The recent success of mechanical thrombectomy trials has led to a major change in the management of patients presenting with stroke. However, despite the wealth of data provided by the 5 major trials (the Multicentre Randomized Clinical Trial of Endovascular Treatment for Acute Ischaemic Stroke in the Netherlands [MR CLEAN], the Randomized Trial of Revascularisation with Solitaire FR Device versus Best Medical Therapy in the Treatment of Acute Stroke due to Anterior Circulation Stroke within Eight Hours of Symptom Onset [REVASCAT], Endovascular Treatment for Small Core and Anterior Circulation Proximal Occlusion with Emphasis on Minimizing CT to Recanalization Times [ESCAPE], Extending the Time for Thrombolysis in Emergency Neurological Deficits - Intra-Arterial [EXTEND-IA], and Solitaire with the Intention of Thrombectomy as Primary Endovascular Treatment [SWIFT PRIME] [1-5]), several questions still remain unanswered. One of the most important of these is whether or not the results of the trials can be extrapolated to clots located in the distal vasculature and, in particular, the M2 segment of the middle cerebral artery (MCA). Several of the trials (ESCAPE, SWIFT PRIME, and REVASCAT) restricted enrolment of patients to those with clots in the proximal large vessels. Patients with occlusion of the M2 branches were included in the MR CLEAN and EXTEND-IA trials; however, a total of 4 patients were enrolled into the treatment arm of EXTEND-IA, while 18 patients were enrolled in MR CLEAN. In the remaining trials, some patients were misclassified as having M1 occlusions but were subsequently judged to have M2 occlusions by the core laboratory. In total, 51 patients were enrolled into the treatment arm across all 5 trials, and this represents just under $4 \%$ of all patients enrolled $(n=1,287)$.

We sought to determine the outcome of patients with acute ischaemic stroke and confirmed M2 occlusions. We assessed the outcome of patients that underwent mechanical thrombectomy at our institution, and we present our data on patient demographics, associated conditions, collateral status, recanalization rates, peri-procedural complications, imaging and clinical outcome.

\section{Materials and Methods}

From our prospectively maintained database we retrospectively selected all patients that met our inclusion criteria which were defined as any patient with a thromboembolic occlusion of the M2 segment of the MCA on pre-operative imaging and admitted to our institution for mechanical thrombectomy between January 2008 and August 2016. The anatomical definition we chose for the M2 segment was the same as that used in the STAR, SWIFT and SWIFT PRIME studies and conformed to the original classification of Fischer [6]. The definition of M2 was as follows: vertical MCA branches in the Sylvian fissure originating at the genu and extending to the next genu at the level of the operculum; if the anterior temporal artery arises from the horizontal M1 segment, it will not be considered an M2 branch.

A neurologist examined all patients at admission, and this included the evaluation of the National Institutes of Health Stroke Scale (NIHSS) score. Patients with suspected acute ischaemic stroke underwent appropriate imaging, either computed tomography (CT) or magnetic resonance imaging (MRI). Those patients that underwent CT imaging had an un-enhanced CT scan as well as a CT angiogram. Those patients that underwent MRI had axial diffusion-weighted imaging (DWI), fluid-attenuated inversion recovery (FLAIR), susceptibility-weighted imaging (SWI) and time-of-flight MR angiography sequences to evaluate them for further treatment with either thrombolysis and/or mechanical thrombectomy. Imaging was performed from the aortic arch to the vertex.

\section{Stroke Therapy}

The use of intravenous thrombolysis followed national and international guidelines and was applied only if the patients presented within $4.5 \mathrm{~h}$ of observed symptom onset and if there were no contraindications. The patients were determined to be candidates for mechanical thrombectomy after discussion between the treating neurologist and the neurointerventionist. Mechanical thrombectomy was only offered if an acute 


\begin{tabular}{l|l}
\hline DOI: $10.1159 / 000458161$ & $\begin{array}{l}\text { C } 2017 \text { S. Karger AG, Basel } \\
\text { www.karger.com/ine }\end{array}$ \\
\hline $\begin{array}{l}\text { Bhogal et al.: Mechanical Thrombectomy for M2 Occlusions: A Single-Centre } \\
\text { Experience }\end{array}$
\end{tabular}

occlusion could be demonstrated on pre-operative imaging and if salvageable brain tissue was thought to be present by the diagnostic and interventional neurologists. An upper age limit for performing mechanical thrombectomy is not used at our institution; rather, the pre-morbid status of the patient is taken into consideration along with co-morbidities and the will of the patient or family members.

All patients underwent mechanical thrombectomy under general anaesthesia. They underwent thrombectomy with stent retrievers and either a balloon guide catheter or distal aspiration catheter.

Post-Interventional Management

All patients were admitted to the neuro-intensive care or stroke unit after mechanical thrombectomy. They had routine follow-up imaging with either CT or MRI 24-36 h after intervention. Follow-up assessment, including modified Rankin Scale (mRS) score, was obtained at 90 days by an inpatient hospital visit or telephone interview with a neurologist [7].

\section{Data Collection}

Data collection included baseline demographics (age and sex), medical history (including history of diabetes mellitus, hypercholesterolaemia, hypertension and atrial fibrillation), smoking history, time of symptom onset and NIHSS score to assess severity. The Alberta Stroke Program Early CT (ASPECT) score was calculated for all patients on axial CT or DWI MRI sequences. The number of passes to obtain the final result was recorded. The final angiographic outcome was recorded using the Thrombolysis in Cerebral Infarction Scale (TICI) [8]. Post-treatment repeat imaging, at 24-36 h, was performed and the ASPECT score noted. The presence of haemorrhage was also recorded. Intra-cranial haemorrhage was classified according to the method used in the ECASS trials: parenchymal haematoma (PH-1 and $\mathrm{PH}-2)$ and haemorrhagic infarction (HI-1 and HI-2) [9].

\section{Results}

\section{Demographics}

Between January 2008 and August 2016 we identified 106 patients that underwent mechanical thrombectomy for M2 occlusions and met our inclusion criteria. The baseline characteristics are shown in Table 1 . The mean age of the patients was $68 \pm 13.8$ years, and 58 patients (54.7\%) were male. Associated medical conditions were common with $70.7 \%$ of the patients having a background of hypertension and just over half of the patients having atrial fibrillation. The main suspected cause of the thromboembolism was cardiac embolism, which was thought to represent the underlying cause in $43.4 \%$ of the patients.

\section{Admission Status}

The admission NIHSS score was recorded for all patients. The majority (54.7\%) of the patients presented with moderate stroke (NIHSS score 5-15) with a similar number of patients presenting with minor (NIHSS score 1-4) and moderately severe (NIHSS score 16-20) stroke. Nine patients $(8.49 \%)$ presented with very severe stroke (NIHSS scale $\geq 21$ ). The mean NIHSS score was $11.8 \pm 7.02$. The average pre-operative ASPECT score was 8.5 (range 4-10). Twenty-three patients received intravenous (IV) alteplase (tissue plasminogen activator [tPA]) prior to mechanical thrombectomy (mean $55.5 \mathrm{mg}$ ).

\section{Angiographic and Procedural Results}

Stent retrievers were used in all cases. In 78 cases, the pREset stent (Phenox, Bochum) was used, in 16 cases the pREset LT (Phenox) was used, and in 12 cases the Solitaire (Covidien) was used. The mean number of thrombectomy attempts was 1.8 (range 1-8). The mean duration of the procedure was $103 \pm 3.4 \mathrm{~min}$, and the mean time to recanalization in the 82 patients with confirmed time of onset was $399 \pm 7.5$ min (Table 1 ). A TICI $\geq 2 \mathrm{~b}$ result was achieved in $90.5 \%$ of the patients, and $68.9 \%$ achieved TICI 3 (Table 2). 


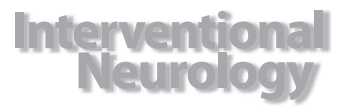

Table 1. The baseline, pre-operative and operative data for the M2 cohort

\begin{tabular}{l|l}
\hline Intervent Neurol 2017;6:117-125 \\
\hline DOI: 10.1159/000458161 & $\begin{array}{l}\text { @ 2017 S. Karger AG, Basel } \\
\text { www.karger.com/ine }\end{array}$ \\
\hline
\end{tabular}

Bhogal et al.: Mechanical Thrombectomy for M2 Occlusions: A Single-Centre Experience

$\begin{array}{lc}\text { Age, years } & 68 \pm 13.8 \\ \text { Male } & 58(54.7) \\ \text { Associated conditions } & \\ \quad \text { Atrial fibrillation } & 54(50.9) \\ \quad \text { Diabetes mellitus } & 31(29.2) \\ \quad \text { Hypertension } & 75(70.7) \\ \quad \text { Hypercholesterolaemia } & 29(27.3) \\ \quad \text { Smoker } & 21(19.8) \\ \text { Suspected cause } & \\ \quad \text { Cardiac embolism } & 46(43.4) \\ \quad \text { Extra-cranial atherosclerosis } & 22(20.8) \\ \quad \text { Dissection } & 3(2.8) \\ \quad \text { Unknown } & 35(33) \\ \text { NIHSS score on admission } & \\ \quad \text { 0 } & 1(0.9) \\ \text { 1-4 } & 17(16) \\ \text { 5-15 } & 58(54.7) \\ \text { 16-20 } & 21(19.8) \\ \text { 21-42 } & 9(8.49) \\ \text { Pre-operative MRI } & 47(44.3) \\ \text { Pre-operative CT } & 59(55.7) \\ \text { Pre-operative ASPECT score } & 8.5 \pm 1.7 \\ \text { Pre-operative MRI ASPECT score } & 7.6 \pm 1.4 \\ \text { Pre-operative CT ASPECT score } & 9.3 \pm 1.5 \\ \text { Side } & \\ \text { Left } & 50(47.1) \\ \text { Right } & 56(52.9) \\ \text { Duration of procedure, min } & 103 \pm 3.4 \\ \text { Mean No. of thrombectomy attempts (range) } & \\ \text { Time from stroke onset to recanalization, min } & \\ & \\ & \end{array}$

Values are means \pm standard deviations or $n(\%)$ unless otherwise indicated. NIHSS, National Institutes of Health Stroke Scale; MRI, magnetic resonance imaging; CT, computed tomography; ASPECT, Alberta Stroke Program Early CT. ${ }^{\text {a }} n=82$.

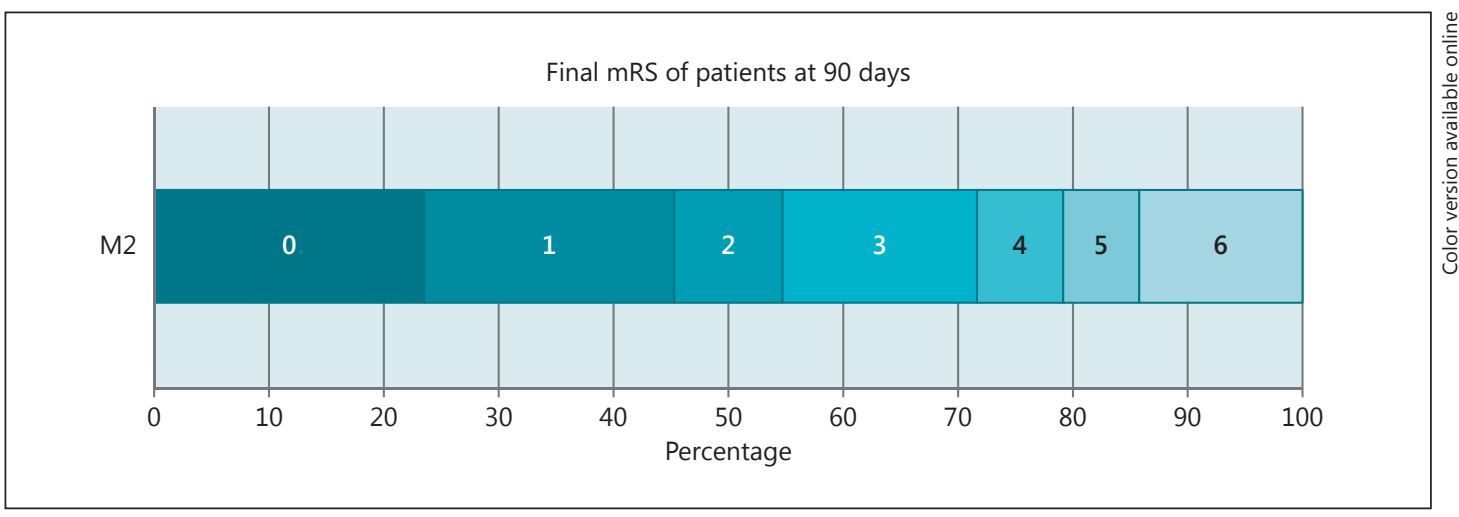

Fig. 1. Ninety-day mRS score of patients with M2 thrombectomy. mRS, modified Rankin Scale. 


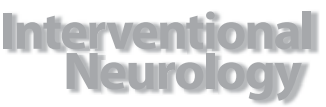

Table 2. The post-procedural imaging outcome, clinical outcome and 90-day outcome for our cohort

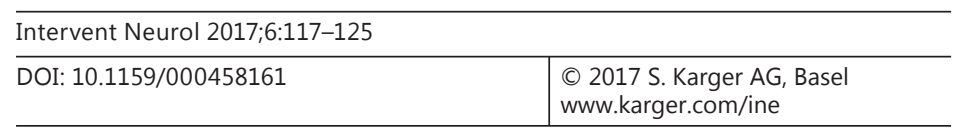

Bhogal et al.: Mechanical Thrombectomy for M2 Occlusions: A Single-Centre Experience

$\begin{array}{lc}\text { Post-operative ASPECT score }(24-36 \mathrm{~h}) & 7.2 \pm 1.7 \\ \text { Post-operative haemorrhage } & \\ \text { None } & 78(73.6) \\ \text { SAH } & 6(5.7) \\ \text { HI-1 } & 6(5.7) \\ \text { HI-2 } & 6(5.7) \\ \text { PH-1 } & 6(5.7) \\ \text { PH-2 } & 4(3.8) \\ \text { SICH } & 5(4.71) \\ \text { TICI } \geq 2 b & 96(90.5) \\ \text { TICI } 3 & 73(68.9) \\ \text { Ninety-day mRS score } & \\ 0 & 25(23.5) \\ 1 & 23(21.7) \\ 2 & 10(9.4) \\ 3 & 18(16.9) \\ 4 & 8(7.5) \\ 5 & 7(6.6) \\ 6 & 15(14.2)\end{array}$

Values are means \pm standard deviations or $n(\%)$. ASPECT, Alberta Stroke Program Early CT; SAH, subarachnoid haemorrhage; HI, haemorrhagic infarction; $\mathrm{PH}$, parenchymal haematoma; SICH, symptomatic intracranial haemorrhage; TICI, Thrombolysis in Cerebral Infarction Scale; mRS, modified Rankin Scale.

\section{Post-Procedural and Clinical Outcome}

All patients had follow-up imaging, and the average ASPECT score on imaging at 24$36 \mathrm{~h}$ was 7.2. Seventy-eight patients showed no signs of haemorrhage on follow-up imaging, and 5 patients had symptomatic haemorrhage. We defined symptomatic haemorrhage as a blood clot caused by thrombolysis and/or thrombectomy that was large enough to exert a mass effect on brain tissue outside the infarct, was associated with a distinct deterioration in the neurological status of the patient and occurred within a time frame when the effect of thrombolysis and/or thrombectomy was plausible. Symptomatic intracerebral haemorrhage or intracranial haemorrhage was seen in $26.4 \%$ of the patients.

At 90-day follow-up, 54.6\% of the patients showed a good clinical outcome (mRS score $\leq 2$ ), and $71.5 \%$ showed a moderate clinical outcome. In total, 15 deaths occurred in our cohort (14.2\%). The results are summarised in Table 2 and Figure 1.

\section{Discussion}

The recent positive trial data regarding mechanical thrombectomy have heralded a new age in stroke treatment. Despite this huge leap forward, many questions remain unanswered, including whether the results can be extrapolated to patients younger than 18 years of age, whether mechanical thrombectomy can be used during pregnancy and whether it is effective in the distal vasculature, such as the M2 and A2 branches of the MCA and anterior cerebral artery, respectively. With regard to the latter question, there are some data from the 5 major trials; however, they are insufficient as a basis for firm recommendations as highlighted in the recent update published by the American Heart Association [10]. This position is understandable since prior evidence suggests that IV tPA alone may be adequate. For example, the 
Table 3. Summary of the results from the major studies analysing the effect of mechanical thrombectomy in M2 branches

\begin{tabular}{l|l}
\hline DOI: $10.1159 / 000458161$ & $\begin{array}{l}\text { C 2017 S. Karger AG, Basel } \\
\text { www.karger.com/ine }\end{array}$ \\
\hline Bhogal et al.: Mechanical Thrombectomy for M2 Occlusions: A Single-Centre
\end{tabular}

Bhogal et al.: Mechanical Thrombectomy for M2 Occlusions: A Single-Centre Experience

\begin{tabular}{lclll}
\hline Authors [ref.] & $\begin{array}{l}\text { Patients } \\
\text { treated }\end{array}$ & $\begin{array}{l}\text { TICI } \geq 2 \mathrm{~b}, \\
\%\end{array}$ & $\begin{array}{l}\mathrm{mRS} \leq 2, \\
\%\end{array}$ & $\begin{array}{l}\text { SICH, } \\
\%\end{array}$ \\
\hline Flores et al. [18] & 65 & 78.50 & 60 & 9 \\
Coutinho et al. [19] & 50 & 85 & 60 & 2 \\
Sarraj et al. [21] & 288 & 78 & 62.80 & 5.10 \\
Dorn et al. [20] & 15 & 93 & 60.00 & 6.70 \\
Our study & 106 & 90.5 & 54.60 & 4.70 \\
\hline
\end{tabular}

TICI, Thrombolysis in Cerebral Infarction Scale; mRS, modified Rankin Scale; SICH, symptomatic intracranial haemorrhage.

Interventional Management of Stroke II (IMS II) sub-group analysis of patients with M2 occlusions showed a low rate of recanalization but a high rate of good clinical outcome at 90 days (90-day mRS score $\leq 2$ in 69.5\%); however, only 23 patients with M2 occlusions were included [11]. Conversely, Rahme et al. [12] identified patients from the Prolyse in Acute Cerebral Thromboembolism II database with M2 occlusion and showed that a favourable outcome was seen in $53.5 \%$ of the patients that achieved TICI 2-3 reperfusion compared to only $28.6 \%$ of those that did not. The IMS III trial showed that TICI $\geq 2 \mathrm{~b}$ reperfusion of solitary M2 occlusions was $44 \%$ and only $23 \%$ for multiple M2 branches. Similarly, the partial or complete reperfusion rate (TICI 2 or 3 ) in patients with CT angiography at baseline and $24 \mathrm{~h}$ was $88 \%$ in the endovascular arm and $77 \%$ in the IV tPA arm [13]. Furthermore, it may be argued that mechanical thrombectomy should be reserved for patients with long clots ( $\geq 8 \mathrm{~mm}$ ), since the likelihood of recanalization in this cohort is very low and since these longer clots are unlikely in the distal vasculature. However, Kamalian et al. [14] showed that $22 \%$ of the patients with an M2 occlusion had clots that were $\geq 8 \mathrm{~mm}$. Therefore, there is still much debate on the role of mechanical thrombectomy in patients with M2 occlusions.

A growing body of evidence suggests that thrombectomy of M2 branches is feasible, safe and may lead to clinical improvement. Sheth et al. [15] recently published their findings comparing the presentation, treatment and outcomes of patients with M1 and M2 occlusions at a single tertiary referral centre. In this study, 61 patients had M1 occlusions and 54 patients had M2 occlusions, defined as division occlusion beyond the bifurcation of M1 [16]. They showed that patients with M2 occlusions presented with small infarcts as well as smaller hypo-perfused areas. However, they also showed that final infarct volumes $\geq 50 \mathrm{~mL}$ [17], which have been shown to be accurate for distinguishing between good and poor clinical outcome, were still seen in 33\% of the patients with M2 occlusions. Similarly, 11\% of the patients with $\mathrm{M} 2$ occlusions had final infarct volumes of $\geq 90 \mathrm{~mL}$, which has been shown to be very specific for poor clinical outcome [17]. This highlights the fact that despite a "distal" occlusion, the volumetric territory of hypo-perfused tissue can be significant, and the authors state that "categorizing patients based on solely M1/M2 distinctions does not fully capture the severity of their stroke."

Flores et al. [18] reviewed their prospectively maintained database and identified 65 patients that presented with an M2 occlusion on initial angiography. In this cohort, the preprocedure NIHSS score was 16, and the majority of the patients were treated with a variety of commercially available stent retrievers (86.2\%), including the Solitaire (Covidien), Trevo Pro (Concentric Medical) and the pREset (Phenox). Overall, they reported TICI $\geq 2 \mathrm{~b}$ in $78.5 \%$ of the patients, and in the patients with a good angiographic outcome the volume of infarct was smaller and a greater percentage of them achieved an mRS score $\leq 2$ ( $66.3 \mathrm{vs.} 30 \%$ ) than in the group of patients who had recanalization TICI $<2 \mathrm{~b}$. These results are in line with those 
reported by Sheth et al. [15] who also observed improved outcomes in patients with good recanalization. They also noted that good recanalization was an independent predictor of good outcome (odds ratio 5.9), whereas IV tPA was not associated with higher recanalization rates (28 vs. 22\%). The use of a stent retriever in an M2 branch was not associated with an increased rate of symptomatic intracranial haemorrhage (SICH), nor did any of the patients that developed SICH (9\%) die. Of interest, the authors reported that those patients with an NIHSS score $>8$ benefited most from recanalization. This may be due to the collateral status of the patients with those presenting with higher NIHSS scores possibly having poorer collaterals. Unfortunately, Flores et al. [18] did not report the collateral status. However, Sheth et al. [15] used perfusion/diffusion mismatch and showed that the final volume of infarcts in patients achieving TICI $\geq 2 \mathrm{~b}$ recanalization was smaller ( $51 \mathrm{vs.} 8 \mathrm{~mL} ; p<0.05$ ) than in those with TICI $<2 \mathrm{~b}$ recanalization and also that there was less infarct expansion (19 vs. $1 \mathrm{~mL} ; p<$ $0.01)$.

More recently, Coutinho et al. [19] published their post hoc analysis of patients with M2 occlusions entered into the STAR, SWIFT and SWIFT PRIME studies. They compared the outcomes of patients with M2 and M1 occlusions and showed that patients with M2 occlusions had lower presenting NIHSS scores (median 13 vs. 17; $p<0.01$ ) than those with M1 occlusions. They also found no significant differences between the 2 cohorts in terms of successful reperfusion, $\mathrm{SICH}$, device-related complications or mRS score $\leq 2$ at 90 -day followup (60 vs. $56 \%$ ) or mortality (12 vs. $10 \%$ ). Coutinho et al. [19] raise the issue of M2 thrombectomy being technically more challenging given the smaller size of the vessels and state that this may be associated with a greater risk. However, this is not proven in either their data or in the data of Dorn et al. [20] who showed similar rates of SICH in their M1 and M2 cohorts but no complications in the M2 group. While this may be due to selection bias, it appears at the moment that mechanical thrombectomy of occluded M2 branches does not carry an increased risk compared to thrombectomy of the M1 segment.

Sarraj et al. [21] recently performed a multi-centre retrospective cohort study with patients pooled from 10 centres in the US. The aim of this study was to determine the safety and effectiveness of mechanical thrombectomy of M2 occlusions as compared to the best medical therapy. A total of 522 patients were identified of whom 288 underwent mechanical thrombectomy and 234 received best medical therapy. The 2 groups were well matched except for age with patients in the medical therapy group being slightly older. Similarly, there was a difference in thrombolysis rates with a higher rate of IV recombinant IPA in the medical therapy group (74.4 vs. 59.7\%). The NIHSS score on presentation, background medical conditions and the ASPECT score were all well matched. The authors found a higher rate of good outcomes (mRS score $\leq 2$ ) in the mechanical thrombectomy group, where stent retrievers were primarily used in $88.9 \%$, with $62.8 \%$ achieving a good outcome compared to only $35.4 \%$ in the best medical therapy group. The mechanical thrombectomy group had a 3.1 times greater chance of a good outcome compared to the standard management even after adjustment for age, NIHSS score, ASPECT score and use of IV recombinant tPA. Importantly, there was also no statistically significant difference in the rate of SICH. These results support the use of mechanical thrombectomy in patients presenting with M2 occlusion despite the inherent limitations of a retrospective study. Our results are very similar to those of Sarraj et al. [21] and Coutinho et al. [19] with $54.6 \%$ of the patients in our study showing an mRS score $\leq 2$ at 90 days. Similarly, an mRS score $\geq 5$ was seen in $20.8 \%$ of the patients in our cohort and in $19.8 \%$ of the patients in that of Sarraj et al. [21]. Death occurred in $12 \%$ of the Coutinho et al. [19] cohort and in $14.2 \%$ of our cohort, which is again remarkably similar. The results of these studies as well as those of our own study are summarised in Table 3.

Although prospective randomised controlled trials are warranted, it may be argued that enrolment into a trial where 1 treatment modality shows a considerably better effect may be 
unethical. Ultimately, we believe that thrombectomy of an M2 vessel is safe and technically feasible and that appropriate patient selection is key. The appropriate selection will need to involve penumbra-based imaging methods, either CT perfusion or MR diffusion/perfusion mismatch, and we should not consider restricting the treatment based on the anatomical location of the clot but should rather look for a suitable mismatch ratio and core infarct volume. This would be a more pathophysiological rather than a purely anatomical approach. This idea has been proposed in the past by Kakuda et al. [22] who suggested that a mismatch ratio of 2.6 gave a $90 \%$ sensitivity and a $83 \%$ specificity for predicting favourable outcome in patients that achieve early reperfusion (odds ratio 31.5). We believe that further studies of this nature are urgently required in order to optimise patient selection and avoid potential futile treatment.

Our study has several limitations inherent in a retrospective design. We had no control group with which we could compare IV thrombolysis, recanalization rates and clinical outcome.

\section{Conclusion}

There is growing evidence that mechanical thrombectomy of M2 vessels is technically feasible and carries a high rate of technical success and good long-term outcomes. Although data from randomised controlled trials are lacking, we believe that M2 vessels should be considered for mechanical recanalization performed by experienced operators.

\section{Statement of Ethics}

As this was a retrospective study, institutional review board approval was not required.

\section{Disclosure Statement}

M. Aguilar Pérez and P. Bhogal serve as proctors and consultants for Phenox GmbH with moderate financial compensation. H. Henkes is a co-founder and shareholder of Phenox GmbH. The other authors have no potential conflicts of interest. This research received no specific grant from any funding agency in the public, commercial or not-for-profit sectors.

\section{References}

1 Berkhemer OA, Fransen PSS, Beumer D, van den Berg LA, Lingsma HF, Yoo AJ, et al: A randomized trial of intraarterial treatment for acute ischemic stroke. N Engl J Med 2015;372:11-20.

2 Goyal M, Demchuk AM, Menon BK, Eesa M, Rempel JL, Thornton J, et al: Randomized assessment of rapid endovascular treatment of ischemic stroke. N Engl J Med 2015;372:1019-1030.

3 Saver JL, Goyal M, Bonafe A, Diener H-C, Levy EI, Pereira VM, et al: Stent-retriever thrombectomy after intravenous t-PA vs. t-PA alone in stroke. N Engl J Med 2015;372:2285-2295.

4 Campbell BCV, Mitchell PJ, Kleinig TJ, Dewey HM, Churilov L, Yassi N, et al: Endovascular therapy for ischemic stroke with perfusion-imaging selection. N Engl J Med 2015;372:1009-1018.

5 Jovin TG, Chamorro A, Cobo E, de Miquel MA, Molina CA, Rovira A, et al: Thrombectomy within 8 hours after symptom onset in ischemic stroke. N Engl J Med 2015;372:2296-2306.

6 Fischer E: Lageabweichungen der vorderen Hirnarterie im Gefässbild. Zentralbl Neurochir 1938;3:300-313.

7 Savio K, Pietra GLD, Oddone E, Reggiani M, Leone MA: Reliability of the modified Rankin Scale applied by telephone. Neurol Int 2013;5:e2.

8 Goyal M, Fargen KM, Turk AS, Mocco J, Liebeskind DS, Frei D, et al: 2C or not 2C: defining an improved revascularization grading scale and the need for standardization of angiography outcomes in stroke trials. J Neurointerv Surg 2014;6:83-86. 
9 Berger C, Fiorelli M, Steiner T, Schäbitz WR, Bozzao L, Bluhmki E, et al: Hemorrhagic transformation of ischemic brain tissue: asymptomatic or symptomatic? Stroke J Cereb Circ 2001;32:1330-1335.

10 Powers WJ, Derdeyn CP, Biller J, Coffey CS, Hoh BL, Jauch EC, et al: 2015 American Heart Association/American Stroke Association focused update of the 2013 guidelines for the early management of patients with acute ischemic stroke regarding endovascular treatment: a guideline for healthcare professionals from the American Heart Association/American Stroke Association. Stroke J Cereb Circ 2015;46:3020-3035.

11 Tomsick T, Broderick J, Carrozella J, Khatri P, Hill M, Palesch Y, et al: Revascularization results in the Interventional Management of Stroke II trial. AJNR Am J Neuroradiol 2008;29:582-587.

12 Rahme R, Abruzzo TA, Martin RH, Tomsick TA, Ringer AJ, Furlan AJ, et al: Is intra-arterial thrombolysis beneficial for M2 occlusions? Subgroup analysis of the PROACT-II trial. Stroke J Cereb Circ 2013;44:240-242.

13 Broderick JP, Palesch YY, Demchuk AM, Yeatts SD, Khatri P, Hill MD, et al: Endovascular therapy after intravenous t-PA versus t-PA alone for stroke. N Engl J Med 2013;368:893-903.

14 Kamalian S, Morais LT, Pomerantz SR, Aceves M, Sit SP, Bose A, et al: Clot length distribution and predictors in anterior circulation stroke: implications for intra-arterial therapy. Stroke J Cereb Circ 2013;44:3553-3556.

15 Sheth SA, Yoo B, Saver JL, Starkman S, Ali LK, Kim D, et al: M2 occlusions as targets for endovascular therapy: comprehensive analysis of diffusion/perfusion MRI, angiography, and clinical outcomes. J Neurointerv Surg 2015;7:478-483.

16 Higashida RT, Furlan AJ, Roberts H, Tomsick T, Connors B, Barr J, et al: Trial design and reporting standards for intra-arterial cerebral thrombolysis for acute ischemic stroke. Stroke J Cereb Circ 2003;34:e109-e137.

17 Yoo AJ, Chaudhry ZA, Nogueira RG, Lev MH, Schaefer PW, Schwamm LH, et al: Infarct volume is a pivotal biomarker after intra-arterial stroke therapy. Stroke J Cereb Circ 2012;43:1323-1330.

18 Flores A, Tomasello A, Cardona P, de Miquel MA, Gomis M, Garcia Bermejo P, et al: Endovascular treatment for M2 occlusions in the era of stentrievers: a descriptive multicenter experience. J Neurointerv Surg 2015;7: 234-237.

19 Coutinho JM, Liebeskind DS, Slater L-A, Nogueira RG, Baxter BW, Levy EI, et al: Mechanical thrombectomy for isolated M2 occlusions: a post hoc analysis of the STAR, SWIFT, and SWIFT PRIME studies. AJNR Am J Neuroradiol 2016;37:667-672.

20 Dorn F, Lockau H, Stetefeld H, Kabbasch C, Kraus B, Dohmen C, et al: Mechanical thrombectomy of M2-occlusion. J Stroke Cerebrovasc Dis 2015;24:1465-1470.

21 Sarraj A, Sangha N, Hussain MS, Wisco D, Vora N, Elijovich L, et al: Endovascular therapy for acute ischemic stroke with occlusion of the middle cerebral artery M2 segment. JAMA Neurol 2016;73:1291-1296.

22 Kakuda W, Lansberg MG, Thijs VN, Kemp SM, Bammer R, Wechsler LR, et al: Optimal definition for PWI/DWI mismatch in acute ischemic stroke patients. J Cereb Blood Flow Metab 2008;28:887-891. 